\title{
Recovery of Cochlear and Vestibular Function after Labyrinthine Haemorrhage
}

\author{
Recuperação das Funções Coclear e Vestibular após Hemorragia Labiríntica
}

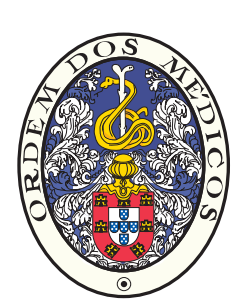

\author{
José ARAÚJO-MARTINS ${ }^{1}$, Patrícia MELO ${ }^{1}$, Cristóvão RIBEIROํ, Ezequiel BARROS ${ }^{1}$ \\ Acta Med Port 2014 Sep-Oct;27(5):649-651
}

\section{ABSTRACT}

Inner ear haemorrhage is a rare disorder with disabling symptoms. Prognosis is generally considered to be poor with essentially no chance of functional recovery. The most common aetiologies are related to blood dyscrasias, anticoagulant therapy or local trauma. The association with autoimmune diseases is exceptional. The authors report a case of sudden deafness with vertigo in a patient with rheumatoid arthritis, caused by labyrinthine haemorrhage. Clinical picture and progress of audiovestibular function are described along with imagiological features from magnetic resonance imaging. Inner ear haemorrhage is a rare disorder with disabling symptoms and poor prognosis. To the best of the authors' knowledge, this is the first case described with documented vestibular function recovery following labyrinthine haemorrhage.

Keywords: Ear, Inner; Hearing Loss, Sudden; Hemorrhage; Vertigo; Vestibular Evoked Myogenic Potentials; Vestibular Function Tests; Vestibule, Labyrinth.

\section{RESUMO}

A hemorragia do ouvido interno é uma doença rara com sintomas incapacitantes e mau prognóstico funcional. As etiologias mais comuns estão relacionadas com discrasias sanguíneas, terapêutica anticoagulante ou traumatismo local. A associação com doenças autoimunes é excecional. Os autores relatam um caso de surdez súbita e vertigem em doente com artrite reumatóide, causada por hemorragia labiríntica. O quadro clínico e a evolução da função audiovestibular são descritos juntamente com os achados imagiológicos em ressonância magnética. Tanto quanto é do conhecimento dos autores, este é o primeiro caso descrito de recuperação da função vestibular após hemorragia labiríntica.

Palavras-chave: Ouvido Interno; Surdez Súbita; Hemorragia; Vertigem; Potenciais Miogénicos Evocados Vestibulares Cervicais; Testes Audiovestibulares; Vestíbulo do Labirinto.

\section{INTRODUCTION}

The annual incidence of sudden sensorineural hearing loss (SNHL) has been considered at around 5-20 cases per 100000 individuals ${ }^{1}$ corresponding to 15000 new cases worldwide. ${ }^{2}$ Its etiology is established in about $10-15 \%$ of cases. ${ }^{3,4}$

Labyrinthine haemorrhage is a rare cause of sudden SNHL with few reports in the literature. It may be traumatic or spontaneous, due to hematologic malignancies, bleeding disorders, anticoagulant therapy, intracranial tumour or post-operative bleeding. ${ }^{4}$ Generally, it is associated with severe hearing loss and imbalance. When reviewing the literature, only two cases reporting improvement in hearing function could be found. ${ }^{5,6}$

The authors describe the clinical, functional and imagiological findings in a patient with rheumatoid arthritis who suffered labyrinthine haemorrhage and partly recovered cochlear and vestibular functions.

\section{CASE REPORT}

A 61-year-old Caucasian woman presented to the Otolaryngology Emergency Department with sudden onset vertigo, imbalance, nausea and vomiting. She reported a sudden and rapidly progressive right-sided hearing loss, tinnitus and aural fullness during the previous week. Her medical history was relevant for rheumatoid arthritis, medicated with etanercept, adalimumab, methylprednisolone, salazopirin, and naproxen, among others.

On admission, she showed spontaneous left-beating horizontal-torsional nystagmus with increasing drift velocity at left gaze. The horizontal head-impulse test (HIT) was positive on the right side on clinical observation. She could stand without support but had great instability while walking. There were no other abnormal findings on neurologic and otoscopic examinations.

Pure tone audiometry showed profound right-sided SNHL and normal hearing in the opposite ear (Fig. 1a). Tympanogram was normal bilaterally. Brain/inner ear magnetic resonance imaging (MRI) results were consistent with right ear labyrinthine haemorrhage (Fig. 2). Blood tests excluded a bleeding disorder, showed normal erythrocyte sedimentation rate (ESR) and C-reactive protein (CRP) and absent anti-neutrophil cytoplasmic antibodies (ANCA).

Vestibular testing was obtained one week later. Caloric tests showed mild right horizontal canal paresis and cervical vestibular evoked myogenic potentials (cVEMP) were absent on the right (Fig. 3).

The patient began treatment with oral corticosteroids followed by hyperbaric oxygen therapy ( 20 sessions) as per service protocol, with mild improvement in hearing function 
a

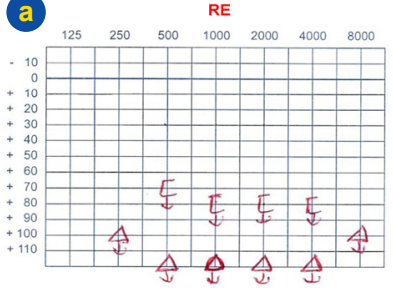

(b)

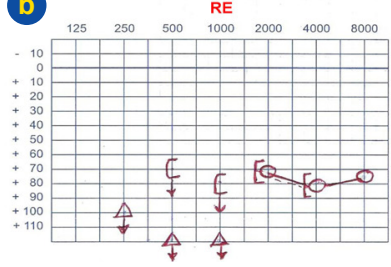

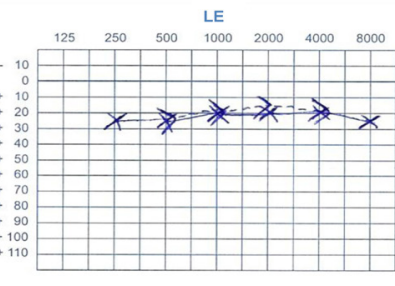

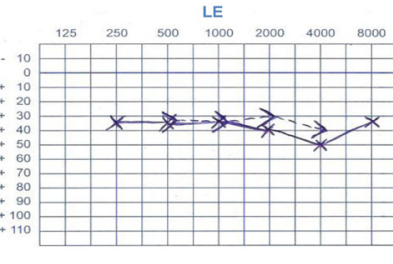

Figure 1 - Pure tone audiometry (RE - right ear, LE - left ear). At presentation the patient had profound right-sided sensorioneural hearing loss and normal hearing on the left (a). After hyperbaric oxygen, mild cochlear recovery is shown in the high frequencies (b).

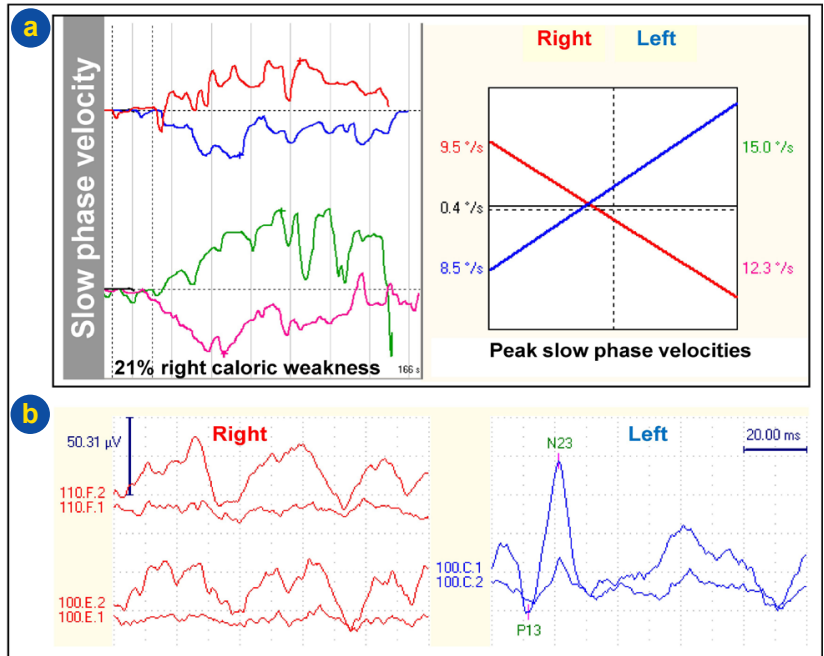

Figure 3 - Vestibular testing one week after presentation. Bithermal caloric testing shows mild right-sided caloric weakness (a) and cVEMP shows normal reflex on the left ear and absent response on the right (b).

at mid-treatment (Fig. 1b). Vertigo and disequilibrium were treated with vestibular rehabilitation exercises.

Five months after disease onset, the patient developed complaints consistent with benign paroxysmal positional vertigo (BPPV). The Dix-Hallpike test was positive for right posterior semicircular canal (SCC) BPPV and the patient was successfully treated with a repositioning Epley manoeuvre. Repeat vestibular testing revealed recovery of cVEMP and persistent horizontal canal paresis on the right side (Fig. 4).

After 18 months of follow-up, the patient's balance improved significantly (Dizziness Handicap Inventory score changed from $92 / 100$ to $46 / 100$ ). Pure tone audiometry was unchanged for both ears. Tinnitus persisted but was well tolerated by the patient.

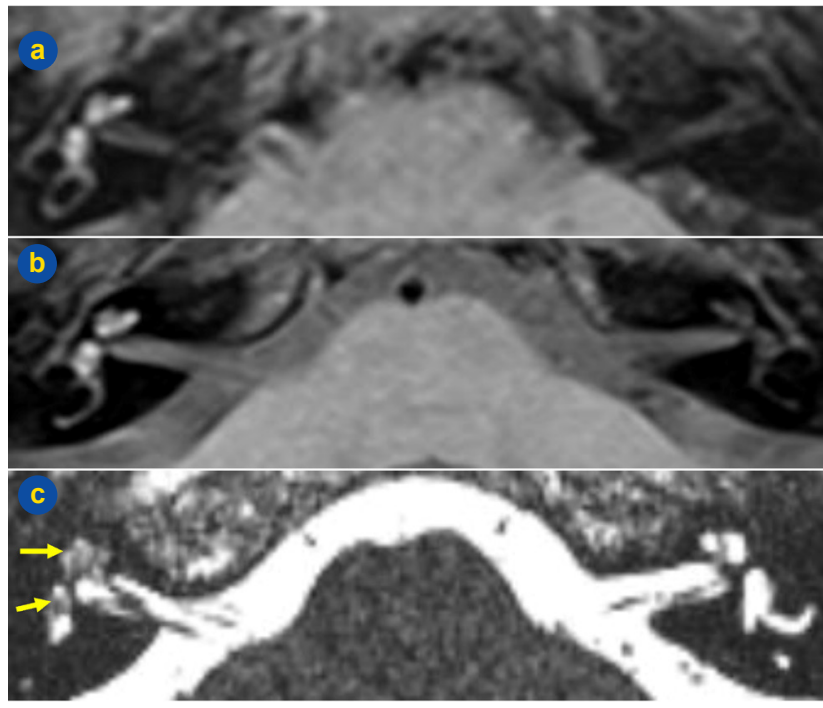

Figure 2 - MRI imaging (compare both sides): right labyrinthine hyperintense signal in T1-weighted fluid attenuated inversion recovery (FLAIR) sequence (a) persisting in T1-weighted sequence with fat suppression (b) and fluid signal loss in T2-weighted constructive interference in steady state (CISS) sequence (c, arrows)

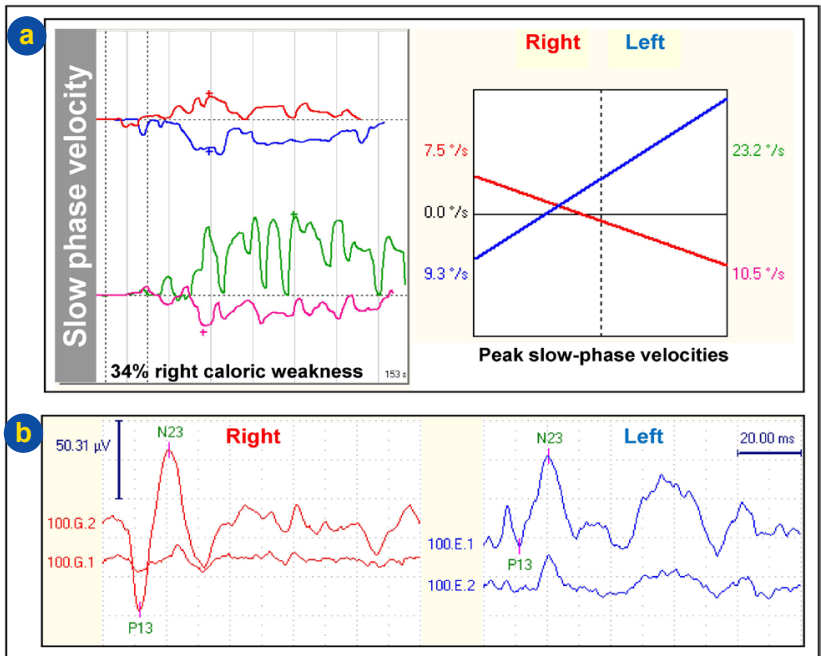

Figure 4 - Vestibular testing five months after acute presentation. Bithermal caloric testing shows persistent right-sided caloric weakness (a) and cVEMP shows recovery on the right ear, with normal amplitude and threshold (b).

\section{DISCUSSION}

The pathophysiology of labyrinthine haemorrhage is incompletely understood due to its rarity and limitations to in vivo studies. In this patient, we can speculate about the contribution of several risk factors. Rheumatoid vasculitis can affect small and medium-sized vessels, but is usually associated with elevated ESR, CRP or $\mathrm{ANCA}^{7}$ which were normal in this patient. Additionally, immune complex deposition may contribute to small-vessel inflammation and organ damage and bleeding may be a complication from long standing therapy with naproxen through decreased platelet aggregation. All these factors may possibly predispose to haemorrhage.

Labyrinthine haemorrhage usually affects both cochlear and vestibular components. In this patient, severe SNHL, 
and altered caloric testing and cVEMP indicate, at least, injury to the cochlea, lateral SCC and saccule. Video-HIT (unavailable at the time) would have helped to characterize individual SCC involvement. Although clinical HIT has limitations, the clear positive findings in the horizontal-VOR were enough to plan additional studies and management. Vertical canal VOR was not assessed as it would not modify further treatment and its predictive value at bedside testing needs further evaluation. It is not clear why vertigo was delayed one week. It may be speculated that haemorrhage followed a cochlear vessel occlusion with the clot dislodging from the basal turn of the cochlea to the saccule. On the other hand, degraded blood metabolites could also lead to spreading oxidative stress or aseptic labyrinthitis. Blood in the endolymph and perilymph changes the hydrostatic pressure, which alters cochlear function and nerve stimulation. ${ }^{5}$

BPPV in this patient may have developed sporadically and unrelated to the case, but there is also a strong possibility that both events were related. After an attack of vestibular neuritis, about one patient in three will develop posterior canal BPPV, usually within three months. ${ }^{8} \mathrm{~A}$ similar mechanism may have hypothetically operated in this case, with labyrinthine haemorrhage causing degeneration of otolithic macula followed by migration of debris into the posterior SCC. According to Murofushi et al in their seminal paper, ${ }^{8}$ posterior SCC BPPV could not develop in patients with absent cVEMP as positional vertigo would only be clinically manifest if the inferior vestibular nerve is intact (normal cVEMP requires normal saccular and nerve function). At acute onset, absent cVEMP indicates dysfunction of the saccule. When posterior SCC BPPV appeared in this patient, recovery of saccular macula function could be anticipated and was confirmed by cVEMP normalization.

$\mathrm{SNHL}$ due to labyrinthine haemorrhage is usually profound and definite. Some series report $100 \%$ of affected patients having persistent SNHL on follow-up. ${ }^{9}$ Two cases were reported to show improved hearing: Shinaharo et al documented an average $30 \mathrm{~dB}$ hearing gain after steroid therapy on a non-profound down-sloping threshold curve ${ }^{6}$

\section{REFERENCES}

1. Byl FM. Seventy-six cases of presumed sudden hearing loss occurring in 1973: prognosis and incidence. Laryngoscope. 1977;87:817-25.

2. Hughes GB, Freedman MA, Haberkamp TJ, Guay ME. Sudden sensorioneural hearing loss. Otolaryngol Clin North Am. 1996;29:393405.

3. Rauch SD. Clinical practice: idiopathic sudden sensorineural hearing loss. N Engl J Med. 2008;359:833-40.

4. Herrero-Agustín J, González Martín FM, Pinilla Urraca M, Laguna Ortega D, de la Fuente Hernández R. Cochlear hemorrhage. Unusual cause of sudden sensorineural deafness. Acta Otorrinolaringol Esp. 2002;53:363-8.

5. Salomone R, Abu TA, Chaves AG, Bocalini MC, Vicente Ade O, Riskalla $\mathrm{PE}$. Sudden hearing loss caused by labyrinthine hemorrhage. Braz J Otorhinolaryngol. 2008;74:776-9.

6. Shinohara S, Yamamoto E, Saiwai S, Tsuji J, Muneta Y, Tanabe M, et al. Clinical features of sudden hearing loss associated with a high signal in the labyrinth on unenhanced T1-weighted magnetic resonance imaging. and Salomone et al reported an average $20 \mathrm{~dB}$ hearing gain after unspecified medical therapy. ${ }^{5}$ This patient's recovery was restricted to higher frequencies.

Initial therapy was increased oral corticosteroids as there were no contraindications and because studies suggest they are as effective as intratympanic corticosteroids (ITC) for first-line treatment, ${ }^{10}$ with less cost and discomfort for the patient. Despite recent clinical guidelines, ${ }^{10}$ there are no criteria as to what level of residual hearing loss best qualifies a patient to salvage therapy with ITC. Salvage therapy with hyperbaric oxygen was chosen in this case because there was no significant hearing recovery after oral steroids and evidence suggests ITC is unlikely to benefit these patients, ${ }^{11}$ while hyperbaric oxygen therapy might still prove useful. ${ }^{10}$

Immunosuppressive and hyperbaric oxygen treatments might have helped recovery by increasing ciliated cell survival or decreasing oedema in affected areas. Vertigo and disequilibrium improved due to central compensation and delayed recovery of saccular dynamic function. Tinnitus habituation is a known and desired phenomenon which could have enhanced the patient's tolerance to this symptom.

The disability caused by labyrinthine haemorrhage makes implementing the best therapy as soon as possible very important. Clinicians should be alert for this diagnosis and contribute with their experience in the literature to help solve currently unanswered questions. This clinical report stresses the importance of cVEMP testing in the assessment of the dynamic function of otolithic organs.

\section{OBSERVATIONS}

This case was the subject of an oral presentation in the congress "Otoneuro 2013", promoted by the Portuguese Association of Otoneurology (APO) in Vila Nova de Gaia, June, 2013.

\section{CONFLICTS OF INTEREST}

The authors declared no conflicts of interest.

\section{FUNDING SOURCES}

No subsidies or grants contributed to this work.
Eur Arch Otorhinolaryngol. 2000;257:480-4.

7. Radic M, Kaliterna DM, Radic J. Overview of vasculitis and vasculopathy in rheumatoid arthritis-something to think about. Clin Rheumatol. 2013;32:937-42.

8. Murofushi T, Halmagyi GM, Yavor RA, Colebatch JG. Absent vestibular evoked myogenic potentials in vestibular neurolabyrinthitis - an indicator of inferior vestibular nerve involvement? Arch Otolaryngol Head Neck Surg. 1996;122:845-8.

9. Dubrulle F, Kohler R, Vincent C, Puech P, Ernst O. Differential diagnosis and prognosis of T1-weighted post-gadolinium intralabyrinthine hyperintensities. Eur Radiol. 2010;20:2628-36.

10. Stachler RJ, Chandrasekhar SS, Archer SM, Rosenfeld RM, Schwartz SR, Barrs DM, et al. Clinical practice guideline: sudden hearing loss. Otolaryngol Head Neck Surg. 2012;146:S1.

11. Spear SA, Schwartz SR. Intratympanic steroids for sudden sensorineural hearing loss: a systematic review. Otolaryngol Head Neck Surg. 2011;145:534-43 


\section{Recovery of Cochlear and Vestibular Function after Labyrinthine Haemorrhage}

Acta Med Port 2014:27:649-651

Publicado pela Acta Médica Portuguesa, a Revista Científica da Ordem dos Médicos

Av. Almirante Gago Coutinho, 151

1749-084 Lisboa, Portugal.

Tel: +351218428215

E-mail: submissao@actamedicaportuguesa.com

www.actamedicaportuguesa.com

ISSN:0870-399X | e-ISSN: 1646-0758

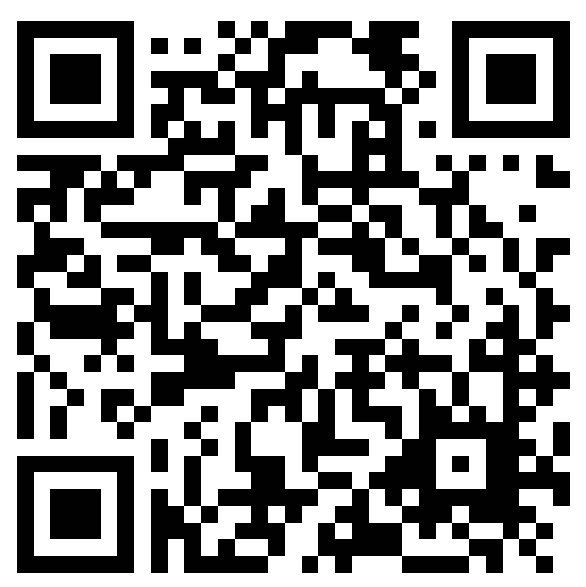

